
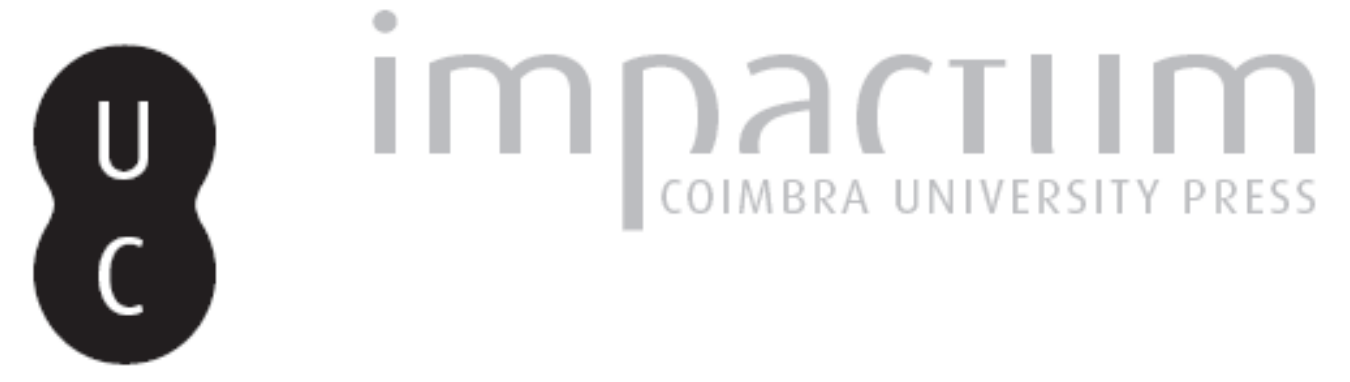

\title{
[Recensão a] Sousa, Rogério - Iniciação e mistério no Antigo Egipto: o caminho de transformação do coraçăo
}

\author{
Autor(es): $\quad$ Araújo, Luís Manuel
}

Publicado por: Centro de História da Universidade de Lisboa

URL persistente:

URl:http://hdl.handle.net/10316.2/23653

DOI:

DOI:http://dx.doi.org/10.14195/0871-9527_21_17

Accessed : $\quad$ 26-Apr-2023 14:14:34

A navegação consulta e descarregamento dos títulos inseridos nas Bibliotecas Digitais UC Digitalis, UC Pombalina e UC Impactum, pressupõem a aceitação plena e sem reservas dos Termos e Condições de Uso destas Bibliotecas Digitais, disponíveis em https://digitalis.uc.pt/pt-pt/termos.

Conforme exposto nos referidos Termos e Condições de Uso, o descarregamento de títulos de acesso restrito requer uma licença válida de autorização devendo o utilizador aceder ao(s) documento(s) a partir de um endereço de IP da instituição detentora da supramencionada licença.

Ao utilizador é apenas permitido o descarregamento para uso pessoal, pelo que o emprego do(s) título(s) descarregado(s) para outro fim, designadamente comercial, carece de autorização do respetivo autor ou editor da obra.

Na medida em que todas as obras da UC Digitalis se encontram protegidas pelo Código do Direito de Autor e Direitos Conexos e demais legislação aplicável, toda a cópia, parcial ou total, deste documento, nos casos em que é legalmente admitida, deverá conter ou fazer-se acompanhar por este aviso.

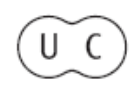



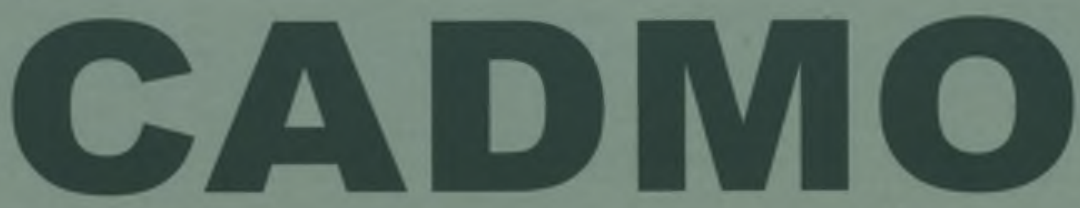

Revista de História Antiga

\author{
Centro de História \\ da Universidade de Lisboa
}

\title{
21
}

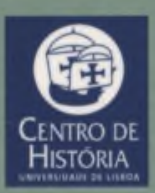

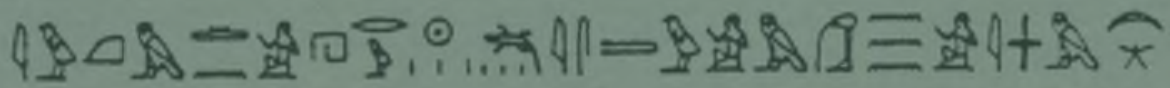

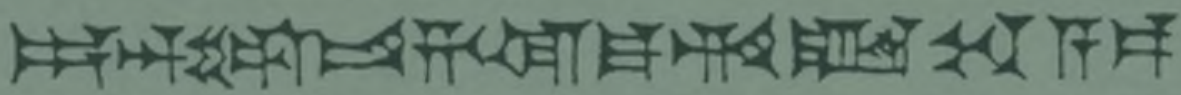

MHNIN AEI $\Delta \mathrm{E} \Theta \mathrm{EA}$ ПH$\Lambda \mathrm{HIA} \triangle \mathrm{E} \Omega$ 
ROGÉRIO SOUSA, Iniciação e Mistério no Antigo Egipto. O caminho de transformação do coração, Lisboa: Ésquilo, 2009, 286 pp., ISBN 978-989-8092-56-4

A bibliografia egiptológica portuguesa tem-se enriquecido nos últimos anos com bons estudos que têm proporcionado aos leitores um vantajoso e aliciante conhecimento de vários aspectos relacionados com a civilização do antigo Egipto. Esta edição é mais um desses contributos, tendo o seu autor produzido neste volume bem paginado e bem ilustrado (e com atraente capa) uma adaptação da sua tese de doutoramento.

O egiptólogo Rogério Sousa, docente do Instituto Universitário de Ciências da Saúde, no Porto, e investigador do CITCEM da Faculdade de Letras da Universidade do Porto, agora em estudos de pós-doutoramento na Alemanha como bolseiro da Fundação para a Ciência e a Tecnologia, depois de um período de pesquisa no Egipto (onde não escava, mas onde recolhe com afinco elementos para o seu trabalho de investigação), oferece-nos nesta obra matéria para proveitosa reflexão.

E logo na introdução fica o leitor elucidado: "O objectivo deste livro consiste, em primeiro lugar, em clarificar os conceitos em torno dos quais gravita o nosso trabalho. É que, por detrás de termos como "iniciação" e "mistério" que, com demasiada frequência, são mal utilizados, ocultam-se noções egípcias muito precisas que é forçoso compreender. Uma vez clarificados os conceitos, este livro pretende contribuir para ampliar a compreensão do tema, mostrando como o ideal da transformação espiritual subjacente à iniciação se encontrava disseminado por toda a literatura e espiritualidade do antigo Egipto, em graus de profundidade muito variáveis, desde os textos sapienciais, aos textos de cariz mágico que visavam facilitar a iniciação do defunto ao mundo da Duat.» - E aqui está como o leitor, munido com esta séria e exordial advertência, fica a saber o que o espera nas páginas que irá fruir e que o «iniciarão» na temática aqui tratada.

Depois da nota prévia e da introdução (pp. 11-14), surge o capítulo 1 compulsando as referências à iniciação egípcia nas fontes clássicas (pp. 
15-28), com um destaque final para o uso sacramental da água presente no culto helenístico de ísis (como já o era na tradição ritual canópica do culto de Osíris), e para o nascimento espiritual.

O capítulo seguinte trata da simbólica e do ritual (pp. 29-108), com as conotações religiosas do termo besi, a iniciação e o contacto com o sagrado, os efeitos fundamentais da iniciação com a iluminação, aqui com a enfatização do conhecimento (rekh) e a transformação espiritual, realçando a precípua iniciação real ao perscrutar os seus eixos de contacto com o sagrado: o templo, o ritual e o texto escrito (e neste caso vem bem a propósito a análise do famoso Conto dos Dois Irmãos, visto como um relato metafórico da iniciação real). Segue-se a iniciação sacerdotal com o ritual de «introdução" do sacerdote e um excurso sobre as origens da moral individual.

No capítulo 3 evoca-se a importante iniciação templária (pp. 109132), sopesando-se os elementos simbólicos do templo egípcio, visto como um caminho de iniciação, onde desempenhavam papel de relevo as provas iniciáticas que tinham o seu fulcral ponto de partida de empolgante percurso nas portas com os seus ferrolhos.

O capítulo 4 sublinha a importância do templo interior, estabelecendo interpelantes comparações com a iniciação interior a que o homem podia aspirar, e realçando o valor dos dois corações do homem (o hati e o ib) para se apreciar a consciência e o dualismo dos termos "cardíacos". Por outro lado, a transformação do coração, que era um pré-requisito para auferir a iniciação, implicava uma vivência escorada no exercício quotidiano da maet para diferenciar o homem justo do homem ímpio - daí a definição antitética entre os modelos de boa conduta e os modelos de má conduta, expressões dicotómicas do combate cósmico que se travava no coração do homem (pp. 133-176).

O último capítulo trata da morte e mistério, com a preparação do cadáver, avultando aqui as fases de mumificação, embalsamamento e colocação dentro do sarcófago, depois a apreciação da morte como isolamento social e a morte como inimigo. Após o cumprimento da cerimónia da abertura da boca (uep-rá) encetava-se o périplo solar onde avultava a lustração como ponto de partida da "saída para o dia" (peret em heru) ingressando o candidato à eternidade na barca de Ré - mas essa saída implicava passar pelo divino tribunal de Osíris e Maet onde tinha lugar o decisivo momento que era o julgamento do defunto para aí ser declarado «justo de voz" ou justificado (maé-kheru) após a "declaração de inocência" com a "confissão negativa" do capítulo 125. para então se iniciar o percurso no templo da Duat (pp. 177-220). 
Na conclusão (pp. 221-238) evidenciam-se os pilares da iniciação egípcia: mente, mito e mistério. Aqui se sublinha a literatura exotérica e a propagação da ética inerente à iniciação, o modelo mítico da iniciação, o mistério e o esoterismo iniciático, as conotações simbólicas da iniciação, para, enfim, se poder concluir que "o estudo da iniciação, enquanto processo que envolvia a transformação da consciência através de uma "dilatação da mente", torna clara a profunda afinidade que no antigo Egipto se estabelecia entre a natureza do corpo, da mente e do próprio cosmos» (p. 232).

A obra remata com os apêndices (pp. 239-256) e a bibliografia (pp. 257-278), com a lista das abreviaturas utilizadas (p. 279). Conclui com uma cronologia que vai da Época Pré-dinástica à Época Greco-romana (p. 281) e um mapa do Egipto (p. 282, não numerada), as quais, salvo melhor opinião, deveriam ir no início do livro para desde logo servir de ponto de apoio temporal e espacial para os leitores. Algumas páginas em branco no final do volume permitem sugerir que a editora podia ter incluído aqui um útil índice remissivo.

Tirando pequenas imprecisões onomásticas, como a redaç̧ão de Horsiesi (p. 96) em vez do mais congruente Horsaisit (p. 97), ou Bakhenkhonsu em vez de Bakenkhonsu (p. 95), nota-se que o Autor entende os nomes egípcios que apresenta, redigindo-os de forma correcta porque conhece 0 seu significado - de facto, convém conhecer bem os nomes na sua forma original egípcia para os apreender e depois verter em transcrição legível e compreensível. É assim que um nome aparentemente complexo como Djedbastetiuefankh (p. 101) se torna claro na sua enfatização semântica tipicamente egípcia: «Bastet diz que ele vive». No que toca à correcção dos nomes apenas se elucida que a estação do ano que abria logo com a desejada inundação nilótica (em meados de Julho) era a de Akhet e não a de Chemu (p. 95).

É ainda de louvar a clareza posta na tradução para português e na interpretação de passagens de conhecidos textos egípcios, como é o caso do complexo «Livro dos Mortos», a começar pelo seu capítulo 125, a chamada "declaração de inocência", que aqui surge em boa e compreensível versão, tal como outros capítulos deste premente vademecum para o Além, que contrastam positivamente com versões deploráveis em português do "Livro dos Mortos" que por aí existem.

Registe-se por fim o benefício da copiosa selecção bibliográfica sobre o tema tratado neste volume, onde se detecta a presença de vários autores portugueses que ultimamente têm publicado os seus trabalhos na área da egiptologia, mostrando que não se trata de um ínvio amon- 
toado de nomes e títulos mas sim um elenco de uma apreciável clareza sem esconsas criptografias. Lá constam as gramáticas e os dicionários consultados, as fontes utilizadas, a bibliografia específica e a bibliografia geral - para grande vantagem dos leitores que queiram continuar a saber mais sobre esta temática.

O Autor pretendia, em suma, e entre outros intentos, "dar um vigoroso estímulo aos estudos de antropologia cultural e da própria egiptologia neste domínio" (p. 14), até porque com a identificação do modelo egípcio de explicação da mente descortina-se bem o processo utilizado para aceder a um mundo superior e luminoso - e esse auspicioso desiderato conseguia-se através da iniciação, aqui nesta obra bem explicitada. Há muitos séculos, no antigo Egipto, os neófitos experimentavam esse sublime passo rumo à transformação que desejavam, e hoje os leitores, a começar pelos estudantes universitários que se debruçam sobre temas de história e cultura pré-clássica nos seus cursos, colhem neste fecundo texto bons ensinamentos que os ajudarão a compreender melhor a mentalidade dos letrados egípcios.

\section{Luís Manuel de Araújo}

EMILY TEETER e JANET H. JOHNSON, The Life of Meresamun. A Temple Singer in Ancient Egypt, Chicago: The University of Chicago, Oriental Institute, 2009, 136 pp., profusamente ilustrado, ISBN 978-1-885923-60-8

Este bem paginado volume é dedicado a uma cantora de Amon que viveu na região tebana, a antiga Uaset, durante a XXI dinastia (século XI a. C.), chamada Meresamon, cujo nome aparece redigido em escrita hieroglífica com a forma típica que se foi impondo na XXI dinastia. O sarcófago e a múmia de Meresamon ("Amon ama-a») foram o núcleo expositivo de uma mostra de objectos pertencentes ao Museu do Instituto Oriental da Universidade de Chicago organizada em 2009. A exposição, baseada no estudo da múmia e do sarcófago de Meresamon, permitiu evocar o Egipto do Terceiro Período Intermediário e a função das cantoras ao serviço de Amon e de outros deuses.

O estudo realizado sobre o sarcófago e a múmia nele contida, bem como o volume daí resultante, tiveram o apoio da empresa Philips, numa mecenática iniciativa que teve no nosso país o seu equivalente na generosa atitude da Siemens em relação à análise radiológica feita às múmias humanas do Museu Nacional de Arqueologia, que foram estudadas na 